\title{
Ficolin 1 Expression is Elevated in the Peripheral Blood Mononuclear Cells of Takayasu's Vasculitis Patients
}

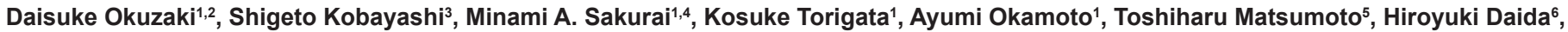 \\ Akihiko Ito ${ }^{4}$ and Hiroshi Nojima ${ }^{1,2 *}$ \\ ${ }^{1}$ Department of Molecular Genetics, Research Institute for Microbial Diseases, Osaka University, 3-1 Yamadaoka, Suita, Osaka 565-0871, Japan \\ ${ }^{2}$ DNA-chip Development Center for Infectious Diseases, Research Institute for Microbial Diseases, Osaka University, 3-1 Yamadaoka, Suita, Osaka 565-0871, Japan \\ 3 Juntendo Koshigaya Hospital, 560 Fukuroyama, Koshigaya, Saitama 343-0032, Japan \\ ${ }^{4}$ Department of Pathology, Faculty of Medicine, Kinki University, 377-2 Ohno-Higashi, Osaka-Sayama, Osaka 589-8511, Japan \\ ${ }^{5}$ Department of Human Pathology, Juntendo University School of Medicine, 2-1-1 Hongo, Bunkyo-ku, 113-8421 Tokyo, Japan \\ ${ }^{6}$ Department of Cardiovascular Medicine, Juntendo University School of Medicine, 2-1-1 Hongo, Bunkyo-ku, 113-8421 Tokyo, Japan

\begin{abstract}
Takayasu's arteritis (TA), a form of vasculitis (angiitis), is a chronic inflammatory disease involving the large blood vessels. This study reports the identification of genes showing increased mRNA levels in peripheral blood mononuclear cells (PBMCs) from TA patients regardless of symptoms or disease activity/inactivity. Of these, mRNA for Ficolin 1 (FCN1) showed a four-fold increase in all eight TA patients examined. Increased FCN1 mRNA levels observed in cDNA microarrays were confirmed by quantitative reverse transcription polymerase chain reaction. Increased FCN1 protein expression was also observed in inflamed regions of the surgical aorta specimens. Moreover, most FCN1-positive cells were also positive for CD68, indicating the presence of monocytic cells, such as macrophages or dendritic cells, which attack infectious agents within the inflamed regions. Taken together, the results suggest that FCN1 mRNA levels in peripheral blood samples may be a diagnostic marker for TA.
\end{abstract}

\section{Introduction}

Takayasu's arteritis (TA), a rare vasculitis presenting mainly in young females, is a chronic, idiopathic, inflammatory disease that affects the aorta and its associated branches [1]. Since the symptoms are non-specific during the acute early phase, (headaches, fever and muscle pains), the diagnosis of TA is often delayed until substantial arterial injury develops [2]. Without proper medical treatment, the disease causes inflammation of the aorta walls and those of its main branches, leading to concentric wall thickening, fibrosis, and thrombus formation. This may then progress to stenosis, occlusion, dilatation or aneurysm of the involved arteries, which are potentially life-threatening conditions $[3,4]$.

The diagnosis of TA is based on a clinical presentation that is heterogeneous but involves two stages: an initial inflammatory process with variable systemic manifestations, and a later "pulseless phase" with occlusion and stenosis of multiple arteries $[3,5]$. Conventional angiography is one of the standard diagnostic procedures. Recent progress in vascular imaging allows the detection of vessel alterations at an earlier stage and better control of the course of disease. Recent progress in computed tomography $(\mathrm{CT})$, magnetic resonance imaging (MRI), and fluorodeoxyglucose positron emission tomography (FDG PET) has led to their increased use in the field of oncology and in patients with inflammatory diseases $[3,6]$. However, these methods are still limited in their ability to accurately quantify the degree of inflammatory disease activity within the arterial walls. Thus, a simple and reliable diagnostic tool is required.

Since large-vessel biopsies are practically impossible to obtain, it is important that a diagnosis of TA is confirmed by laboratory investigations. Such investigations should be simple, as non-invasive as possible, and predict morbidity. A gene marker (that is easily accessible, e.g., from peripheral blood cells) that can specifically diagnose TA patients at an early phase of the disease, regardless of the patient's symptoms or level of disease activity/inactivity, would be very useful. To date, few studies (apart from our own previous work) have been published regarding the genome-wide analysis of TA [7-9].
Therefore, the aim of the present study was to identify new gene markers expressed in peripheral blood mononuclear cells (PBMCs) that can distinguish TA patients (regardless of symptoms) from healthy volunteers. For this purpose, we used high-density oligonucleotide microarrays and found that the mRNA levels of a particular complement factor, Ficolin 1 (FCN1), were markedly up-regulated in PBMCs from all TA patients examined. Immunostaining revealed augmented expression of FCN1 protein within the inflamed regions of surgical specimens of aorta in 4/5 unrelated TA patients, indicating that FCN1 may serve as a marker for the diagnosis of TA.

\section{Patients, Materials and Methods}

\section{Human subjects and Ethical permission}

All TA patients used in this study were diagnosed as TA using angiography according to a previously documented proposal (the ACR criteria and the CHCC criteria) [10] by medical doctors who are rheumatologists and cardio-vascular specialists in Juntendo Hospital, Japan. The study was reviewed and approved by the Research Ethics Committee of Osaka University. Accordingly, written informed consent was obtained from all participants. Serum samples were

*Corresponding author: Hiroshi Nojima, DNA-chip Development Center for Infectious Diseases, Research Institute for Microbial Diseases, Osaka University, 3-1 Yamadaoka, Suita, Osaka 565-0871, Japan, Juntendo Koshigaya Hospital, 560 Fukuroyama, Koshigaya, Saitama 343-0032, Japan, Tel: +81-6-6875-3980; Fax: +81-6-6875-5192; E-mail: snj-0212@biken.osaka-u.ac.jp

Received February 22, 2012; Accepted March 27, 2012; Published April 06, 2012

Citation: Okuzaki D, Kobayashi S, Sakurai MA, Torigata K, Okamoto A, et al (2012) Ficolin 1 Expression is Elevated in the Peripheral Blood Mononuclear Cells of Takayasu's Vasculitis Patients. J Mol Biomark Diagn 2:125. doi:10.4172/21559929.1000125

Copyright: (c) 2012 Okuzaki D, et al. This is an open-access article distributed under the terms of the Creative Commons Attribution License, which permits unrestricted use, distribution, and reproduction in any medium, provided the original author and source are credited 
consecutively obtained regardless of the patient's symptoms and level of disease activity/inactivity.

\section{Preparation of RNA}

RNA was prepared from PBMCs isolated from TA patients and normal volunteers using standard methods [11]. Briefly, heparinized venous blood $(10 \mathrm{~mL})$ was mixed with an equal volume of $2 \%$ dextran/ saline solution and incubated at room temperature for $30 \mathrm{~min}$ to precipitate the red blood cells. The PBMCs in the supernatant were then purified by density-gradient centrifugation on Percoll (density: $1.064 \mathrm{~g} / \mathrm{mL}$ ).

Total RNA was extracted from the PBMC pellets by adding guanidine-thiocyanate solution and the samples were subjected to acid guanidinium-phenol-chloroform extraction followed by ethanol precipitation and DNase I treatment prior to microarray or quantitative reverse transcription polymerase chain reaction (qRT-PCR) analyses.

\section{DNA microarray analysis}

The quality of the RNA samples was examined using the RNA 6000 Nano LabChip Kit (p/n 5065-4476) and an Agilent 2100 Bioanalyzer (G2940BA; Agilent Technologies, Inc., Palo Alto, CA). Total RNA (500 ng) isolated from the PBMCs of each vasculitis patient was examined along with pooled RNA from the normal volunteers (Figure. S1A). Each patient's RNA and the pooled normal RNA were reversetranscribed using oligo-dT primers containing the T7 RNA polymerase promoter sequence, and the resulting cDNA was subjected to in vitro transcription using T7 RNA polymerase so that they were labeled with Cy3 or Cy5 (CyDye, Amersham Pharmacia Biotech, Piscataway, $\mathrm{NJ})$. The Cy5-labeled cRNAs from the vasculitis patients (1625 ng) were then mixed with the same amount of reverse color Cy3-labeled cRNAs from the normal volunteers. Hybridization, rinsing, scanning, and gene analysis were conducted using the Agilent Whole Human Genome Microarray (4x44K G4112F) according to the manufacturer's protocol. The ratio of the $\mathrm{cy} 5 / \mathrm{cy} 3$ was calculated for every probe and the results were analyzed using Subio Basic Plug-in (v1.6; Subio Inc., Aichi, Japan), which allows visualization of microarray data in the form of a heat-map and a line graph. aw data have been accepted in GEO (a public repository for microarray data, aimed at storing MIAME (Minimum Information About Microarray Experiments). Access to data concerning this study may be found under GEO experiment accession number GSE33910 (http://www.ncbi.nlm.nih.gov/geo/ query/acc.cgi?token=prittocsqucugxi\&acc=GSE33910).

\section{Pathway analysis of microarray data}

The microarray data were analyzed using Ingenuity Pathways Analysis (IPA) (Ingenuity Systems, Redwood City, CA; www.ingenuity. com). Briefly, all data sets containing gene identifiers were uploaded into the application along with the corresponding expression values and overlaid onto several inflammatory related networks developed using information contained in the Ingenuity Knowledge Base.

\section{Quantitative real-time PCR}

We performed qRT-PCR in an ABI PRISM 7900 (PE Applied Biosystems, Foster City, CA) using the Assay-on-Demand TaqMan probe and the relevant primers according to the manufacturer's instructions. For FCN1, an assay kit (ID Hs00157572_m1) was purchased from PE Applied Biosystems (Foster City, CA). The following oligonucleotides were used as primers and probes for the GAPDH gene: GAPDH forward primer, 5'-CCATCAATGACCCCTTCATTG-3';
GAPDH reverse primer, 5'-TCTCGCTCCTGGAAGATGGT-3'; and GAPDH TaqMan probe, 5'-VIC-ACCTCAACTACATGGTTTACMGBNFQ-3'. Total RNA (500 ng) was reverse-transcribed using the High Capacity cDNA Archive Kit (ABI). The cDNA was then used as a template for PCR in a $20 \mu \mathrm{L}$ reaction using $2 \times$ Master Mix according to the manufacturer's instructions (TaKaRa, Otsu, Japan). The PCR conditions were as follows: initial denaturation at $95^{\circ} \mathrm{C}$ for $10 \mathrm{~min}$, followed by 40 cycles of denaturation at $95^{\circ} \mathrm{C}$ for $15 \mathrm{~s}$ and annealing/ extension at $60^{\circ} \mathrm{C}$ for $1 \mathrm{~min}$. Each sample was assayed in quadruplicate and the median threshold cycle $\left(C_{\mathrm{T}}\right)$ values were used to calculate the fold change between the treated and control samples. A standard curve was generated from the amplification data for each primer using serial dilutions of PBMC RNA as the template. The fold change values were normalized to GAPDH levels using the standard curve method according to the manufacturer's protocol.

\section{Histological analysis}

Surgical aorta specimens from TA patients were fixed with $10 \%$ buffered formalin, embedded in paraffin, and cut into $4 \mu \mathrm{m}$-thick serial sections. The first sections were stained with hematoxylin and eosin and used for pathological diagnosis of inflamed regions. The other three sections were subjected to immunohistochemistry as described previously. Briefly, deparaffinized sections were autoclaved in $0.1 \mathrm{M}$ citrate buffer, blocked with bovine serum albumin (BSA), and incubated with the indicated primary antibodies diluted in $\mathrm{PBS} / 2 \%$ BSA. Secondary antibody and signal enhancement reactions were performed using the Histofine Simple Stain kit (Nichirei, Tokyo, Japan), and the color was developed with aminoethlcarbazole (Impact AEC; Vector Laboratories, Burlingame, CA). Some sections were double-stained with antibodies against FCN1 and CD68 for immunofluorescence analysis. After the deparaffinized sections were autoclaved and blocked-up as described above, they were incubated with a mixture of anti-FCN1 and anti-CD68 antibodies in PBS/2\% PBS. After washing three times with PBS, the sections were incubated with a mixture of Cy2- and Cy3-labeled donkey antibodies against mouse and rabbit IgG, respectively (Jackson ImmunoResearch Laboratories, PA). Sections were counterstained with hematoxylin to visualize the cell nuclei before being mounted with Ultramount Aqueous Permanent Mounting Medium (DakoCytomation, Glostrup, Denmark).

\section{Results}

\section{Identification of TA-related genes by DNA microarray analysis}

To isolate putative TA-related genes that are up- or down-regulated in the PBMCs of TA patients compared to normal volunteers, genomewide complementary DNA microarray analysis was performed using the Agilent Hu44K array and RNA samples isolated from the PBMCs from eight individual TA patients and 17 normal volunteers, as previously described [12] (Figure. S1A). TA patients were examined regardless of symptoms or disease activity/inactivity (Table 1) because we wanted to obtain a marker that distinguishes TA from normal controls even during its inactive phase.

Analysis of the microarray data revealed that 15 genes were upregulated $>3$-fold in all eight TA patients compared with the normal controls (Figure. 1A, red and blue lines, and Figure. S1B and C). Since TA is a disease caused by aberrant regulation of the immune system, we focused on the complement factor FCN1, whose mRNA levels were increased $>4.0$-fold in all eight TA patients (Fig. 1A, blue line and font). Since two uncharacterized genes (C6orf47 and C19orf56) and 
Citation: Okuzaki D, Kobayashi S, Sakurai MA, Torigata K, Okamoto A, et al. (2012) Ficolin 1 Expression is Elevated in the Peripheral Blood Mononuclear Cells of Takayasu's Vasculitis Patients. J Mol Biomark Diagn 2:125. doi:10.4172/2155-9929.1000125

Page 3 of 7

\begin{tabular}{|c|c|c|c|c|c|c|c|c|}
\hline & Case 1 & Case 2 & Case 3 & Case 4 & Case 5 & Case 6 & Case 7 & Case 8 \\
\hline Age & 34 & 18 & 30 & 61 & 54 & 58 & 56 & 55 \\
\hline Gender & female & female & female & female & female & male & female & female \\
\hline Duration of disease & $\begin{array}{l}\text { 11years and } 3 \\
\text { months }\end{array}$ & 4 months & 8 years & 5 years & 14 months & 15 years & 23 years & 10 years \\
\hline Clinical feature $^{1)}$ & $\begin{array}{l}\text { Mild fever, } \\
\text { decreased } \\
\text { pulsation of left } \\
\text { radial artery }\end{array}$ & $\begin{array}{l}\text { Fever of }>38^{\circ} \mathrm{C} \text {, } \\
\text { bruits at neck } \\
\text { and abdomen, } \\
\text { abdominal pain, } \\
\text { diarhea }\end{array}$ & $\begin{array}{l}\text { Decreased } \\
\text { pulsation of left } \\
\text { radial artery }\end{array}$ & $\begin{array}{l}\text { General fatigue, } \\
\text { shoulder myalgia, } \\
\text { decreased } \\
\text { pulsation of left } \\
\text { radial artery, bruis } \\
\text { at neck }\end{array}$ & $\begin{array}{l}\text { Myalgia, } \\
\text { arthralgia, } \\
\text { general } \\
\text { fatigue }\end{array}$ & $\begin{array}{l}\text { Fever }>38^{\circ} \mathrm{C}, \\
\text { polyalthralgia, } \\
\text { decreased } \\
\text { pulsation of } \\
\text { left radial } \\
\text { artery, bruits } \\
\text { at neck and } \\
\text { abdomen }\end{array}$ & $\begin{array}{l}\text { Fever }>38^{\circ} \mathrm{C} \text {, } \\
\text { polyalthralgia, } \\
\text { decreased } \\
\text { pulsation of left } \\
\text { radial artery, } \\
\text { Raynaud } \\
\text { syndrome }\end{array}$ & $\begin{array}{l}\text { Consciousness } \\
\text { loss, headache, } \\
\text { myalgia, } \\
\text { arthrlargia, } \\
\text { erythema } \\
\text { nodosum, bruit } \\
\text { at both neck, } \\
\text { blurred vision at } \\
\text { left eye }\end{array}$ \\
\hline $\begin{array}{l}\text { Classification of } \\
\text { angiography }\end{array}$ & 1 & V & 1 & 1 & V & V & V & II \\
\hline $\begin{array}{l}\text { Coronary and/ } \\
\text { or pulmonary } \\
\text { involvement }\end{array}$ & C-, P- & C-, P- & C-, P- & C:not done, $\mathrm{P}+$ & C-, P- & C-, P- & C-, P- & $\mathrm{C}+, \mathrm{P}-$ \\
\hline Associated diseases & $\begin{array}{l}\text { Atopic dermatitis, } \\
\text { ovarian cyst }\end{array}$ & $\begin{array}{l}\text { Aortic valve } \\
\text { regargitation }\end{array}$ & $\begin{array}{l}\text { Compression } \\
\text { fractures of } \\
\text { vertebrae, } \\
\text { depression }\end{array}$ & None & $\begin{array}{l}\text { Hypertrophic } \\
\text { myocarditis, } \\
\text { Dementia }\end{array}$ & Uveitis & $\begin{array}{l}\text { Mixed connective } \\
\text { tissue disease, } \\
\text { interstitial } \\
\text { pneumonia, } \\
\text { conprssion } \\
\text { fracture of } \\
\text { vertebrae, } \\
\text { pneumocystis } \\
\text { pneumonia }\end{array}$ & $\begin{array}{l}\text { Myoma uteri, } \\
\text { ovarian cyst }\end{array}$ \\
\hline Disease activity & Moderately active & Active phase & Inactive phase & Inactive phase & Inactive phase & Inactive phase & Inactive phase & Flared \\
\hline Laboratory data $^{2)}$ & 06/21/02 & 06/08/02 & $08 / 22 / 02$ & $12 / 13 / 02$ & $03 / 13 / 03$ & $01 / 07 / 05$ & $01 / 07 / 05$ & 03/01/05 \\
\hline WBC (/mm3) & 8,200 & 8,900 & 4,800 & 4,500 & 6,300 & 9,200 & 14,800 & 10,300 \\
\hline CRP (mg/dl) & 4.1 & 7.7 & 0.1 & 0.2 & 0.1 & 0.3 & 5.1 & 2.4 \\
\hline ESR (/mm/hour) & 36 & 111 & 11 & 13 & 11 & 8 & 17 & 43 \\
\hline $\mathrm{Hb}(\mathrm{g} / \mathrm{dl})$ & 10.6 & 9.8 & 11.7 & 13.7 & 12 & 14.5 & 7.7 & 10.2 \\
\hline Treatment $\mathbf{t}^{3)}$ & $\begin{array}{l}\mathrm{PSL} 5 \mathrm{mg} / \mathrm{d} \text {, } \\
\text { etidronate } \\
\text { disodium } 200 \mathrm{mg} / \mathrm{d}\end{array}$ & PSL40mg/d & $\begin{array}{l}\text { PSL } 12 \mathrm{mg} / \mathrm{d} \text {, } \\
\text { azatioprine } \\
50 \mathrm{mg} / \mathrm{d} \text {, } \\
\text { etidronate } \\
\text { disodium } \\
200 \mathrm{mg} / \mathrm{d}\end{array}$ & Aspirin $100 \mathrm{mg} / \mathrm{d}$ & $\begin{array}{l}\text { Aspirin } \\
100 \mathrm{mg} / \mathrm{d}, \\
\text { dipyridamole } \\
200 \mathrm{mg} / \mathrm{d}\end{array}$ & $\begin{array}{l}\text { PSL5mg/d } \\
\text { aspirin } \\
100 \mathrm{mg} / \mathrm{d} \text {, }\end{array}$ & $\begin{array}{l}\text { PSL } 5 \mathrm{mg} / \mathrm{d} \text {, } \\
\text { antibiotics (micaf } \\
\text { ungin,peatamidin } \\
\text { e,erythromiycin,d } \\
\text { oripenen) }\end{array}$ & $\begin{array}{l}\text { PSL30mg/d, } \\
\text { aspirin } \\
100 \mathrm{mg} / \mathrm{d}, \\
\text { warfarin3mg/ } \\
\text { d,pravastatin } \\
5 \mathrm{mg} / \mathrm{d}\end{array}$ \\
\hline HLA-typing & $\begin{array}{l}\text { A29,31,B51, } \\
\text { B52,DR2 }\end{array}$ & $\begin{array}{l}\text { A2,A24,B35,B52, } \\
\text { DR2,DR4 }\end{array}$ & A24,B52,DR2 & $\begin{array}{l}\text { A11,A31(19),B67, } \\
\text { B61(40), Cw7, } \\
\text { Cw3 }\end{array}$ & B52,DR2 & B39,B52 & N.E & B52 \\
\hline
\end{tabular}

1): All clinical manifestations occurred during the course of disease are described. 2):Data indicate when sample was obtained. 3): Described when sample was obtained. 4):NE: not examined, PSL: prednisolone

$\mathrm{A} 11, \mathrm{~A} 31,(19), \mathrm{B} 67, \mathrm{~B} 61(40), \mathrm{Cw} 7, \mathrm{Cw} 3$

Table 1: Profiles of TA patients used in this study.

12 other genes do not appear to be directly involved in the immune system, we decided not to study them further. We also identified 13 genes that were down-regulated in all eight TA patients; however, none appeared to be related to the immune system, so further analysis was not performed.

It is notable that mRNA levels for C5AR1, CD59 and CD46 were unchanged in patients \#4 and \#5. This may be because they were not treated with prednisolone at that time due to their inactive symptoms; however the other six patients had been treated with prednisolone because their disease was in the active phase. Patient \#4 was followed for almost 5 years, but had not experienced any flare-ups at the time the final blood sample was taken. Patient \#5 was followed for almost 9 years; no flare-ups were identified and no medication for Takayasu's arteritis had been taken when the final blood sample was collected. These data show that up-regulated C5AR1, CD59 and CD46 mRNA levels may serve as a marker for the active phase, whereas up-regulation of FCN1 mRNA levels may serve as a marker regardless of the disease phase (active/inactive).

\section{Examination of other complement factor genes}

The complement system is regulated by more than twenty independent genes. Therefore, to examine whether other complement factor genes were also up- or down-regulated in the eight TA patients, we analyzed the data using Ingenuity Pathways Analysis (Ingenuity Systems, www.ingenuity.com). This powerful ontology search query system allows the rapid visualization of relationships between a set of relevant genes and increases the predictive physiological significance of the enhanced FCN1 expression identified earlier. Indeed, the results showed that membrane cofactor protein (MCP/CD46) was upregulated (Figure. 2A, blue arrow) in a manner similar to that of FCN1 (yellow arrow) in patients with TA. CD59 (green arrow) and C5AR (orange arrow) were moderately up-regulated.

In addition, the heat map derived from the microarray data allowed us to compare the differential expression of the genes by showing the mRNA level of each gene in a color tile format. Each colored tile in the heat map represents a gene expression value; the largest gene expression 

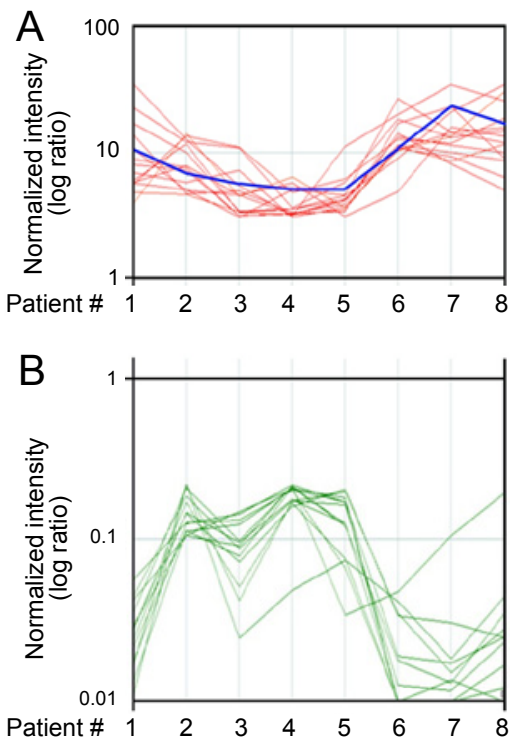

$\begin{array}{llc}\text { Gene name } & \text { Description } & \text { Fold change } \\ \text { PPP1CC } & \text { Protein phosphatase 1, catalytic subunit } & >5.0 \\ \text { FCN1 } & \text { Ficolin 1 } & >4.0 \\ \text { MAN2A2 } & \text { Mannosidase } \alpha \text {, class 2A, member 2 } & >3.5 \\ \text { FAM62B } & \text { Family with sequence similarity 62B } & >3.5 \\ \text { ARPC1B } & \text { Actin related protein 2/3 complex } & >3.0 \\ \text { C6orf47 } & \text { Chr6 open reading frame 47 } & >3.0 \\ \text { C19orf47 } & \text { Chr9 open reading frame 56 } & >3.0 \\ \text { SH3KBP1 } & \text { SH3-domain kinase binding protein 1 } & >3.0 \\ \text { SLC39A11 } & \text { Solute carrier family 39 member 11 } & >3.0 \\ \text { NDUFS8 } & \text { NADH dehydrogenaseFe-S protein 8 } & >3.0 \\ \text { CUL4A } & \text { Culin 4A } & >3.0 \\ \text { FBXO21 } & \text { F-box protein 21, transcript variant 1 } & >3.0 \\ \text { SGSH } & \text { N-sulfoglucosamine sulfohydrolase } & >3.0 \\ \text { TRAPPC3 } & \text { Trafficking protein particle compl } & >3.0 \\ \text { PRKAR1A } & \text { Protein kinase A, regulatory, type I, } \alpha & >3.0\end{array}$

$\begin{array}{llr}\text { Gene name } & \text { Description } & \text { Fold change } \\ \text { DICER1 } & \text { DsRNA-specific endoribonuclease } & <0.22 \\ \text { P704878 } & \text { Unknown } & <0.22 \\ \text { CHPF } & \text { Chondroitin polymerizing factor } & <0.22 \\ \text { TP53I11 } & \text { Tumor protein p53 inducible protein 11 } & <0.22 \\ \text { FLJ38303 } & \text { Unknown } & <0.22 \\ \text { ACF } & \text { Apobec-1 complementation factor } & <0.22 \\ \text { FAM83F } & \text { Family with sequence similarity 83F } & <0.22 \\ \text { CCNT2 } & \text { Cyclin T2 } & <0.22 \\ \text { RIN1 } & \text { Ras and Rab interactor 1 } & <0.22 \\ \text { MG1 } & \text { High molecular weight mucin } & <0.22 \\ \text { FGD6 } & \text { FYVE, RhoGEF and PH domain containing 6 } 60.20 \\ \text { DAO } & \text { D-amino-acid oxidase } & <0.18 \\ \text { THC2285293 } & \text { Unknown } & <0.17 \\ & & \end{array}$

Figure 1: Expression profiles of the genes whose mRNA levels were significantly altered in the PBMCs of TA patients. The Agilent whole human genome DNA microarray was used for this analysis. (A, B) Line-graphs showing 15 (A) or 13 (B) genes whose expression were up-regulated $(>3.0$-fold) or down-regulated $(<0.22$ fold) in all eight TA patients compared with the healthy volunteers. The line for the FCN1 gene is highlighted in blue. The ordinate scale indicates relative log10 ratios. Up- or down-regulated genes are denoted by red lines and red font or green lines and green font, respectively. The blue line in (A) denotes the expression profile of the FCN1 gene (highlighted in a blue font).

values are displayed in red (hot), the smallest values in blue (cool), and the intermediate values in different shades of red (pink) or blue. Gray tiles indicate no change. Indeed, the heat map showed that only FCN1 was up-regulated in all eight TA patients (Figure. 2B, yellow arrow). By contrast, the mRNA levels of MCP/CD46 (blue arrow), CD59 (green arrow) and C5AR (orange arrow) in patients \#4 and \#5 were almost the same as those in the normal volunteers (Figure. 2B). Thus, only FCN1 was identified as a promising TA-related diagnostic marker.

\section{Expression of other immune-related genes}

We next sought to examine whether the expression of other immune-related genes was enhanced in TA patients. Therefore, we performed pathway analysis and constructed a second heat map. Several genes that regulate the interferon (Figure. 3) and toll-like receptor signaling pathways (Figure. 4) showed increased signals in samples from TA patients.

The genes involved in the interferon signaling pathway were signal transducers and activators of transcription (STAT1; Fig. 4, turquoise arrow), proteasome (prosome, macropain) subunit beta type-8 (PSMB8; pink arrow), interferon regulatory factor 1 (IRF1; gray arrow), interferon regulatory factor 9 (IRF9; ocher arrow), interferon gamma receptor 1 (IFGR1/IFGR $\alpha$; black arrow) and interferon gamma receptor 2 (IFGR2/IFGR $\beta$; white arrow). Of these, STAT1, PSMB8, IRF1, IRF9 and IFGR1 showed enhanced signals in all eight TA patients, although the signal intensity was modest in patients \#3, \#4 and \#5. Thus, these genes may be candidate TA-related diagnostic markers. By contrast, IFGR2 showed weak signals in patients \#4 and \#5, and so was not considered as a candidate.

Some of the genes involved in the toll-like receptor signaling pathway also showed increased signals in all eight TA patients (Figure. $4)$; these genes include inhibitor of kappa light polypeptide gene enhancer in B-cells, kinase gamma (IKBKG; navy arrow), myeloid differentiation factor 88 (MYD88; pale brown arrow) and toll-like receptor 6 (TLR6; pale green arrow). However, their signal intensities were not conspicuously high. Thus, they were not considered as candidates. Taken together, we concluded that FCN1 is the most promising TA-related diagnostic marker among the immune-related gene.

\section{qRT-PCR of FCN1 genes in PCMBs from TA patients}

To confirm that the microarray signals actually reflected FCN1 mRNA levels, qRT-PCR was performed using the same RNA samples used for the microarray analysis. Samples from three patients were not analyzed due to a lack of RNA. All the samples analyzed by qRTPCR showed increased FCN1 mRNA levels compared with the normal controls (Figure. 5), confirming the microarray analysis results.

\section{Immunohistochemistry for FCN1 in the arteries of unrelated TA patients}

To demonstrate the usefulness of FCN1 as a TA-related diagnostic marker, we examined augmented FCN1 protein expression within the inflamed regions of surgical aorta specimens from five new TA patients (\#9-13) unrelated to the eight TA patients analyzed previously. Anti-C3 and anti-C4 antibodies were used as negative controls because the mRNA levels of $\mathrm{C} 3$ and $\mathrm{C} 4$ were low in all eight TA patients previously tested (Figure. 2B; thin black arrows). Immunohistochemistry revealed that $4 / 5$ aorta specimens from TA patients reacted strongly with the anti-FCN1 antibody (Figure 6A; Patients 9-12). FCN1 immunoreactive signals were detected in some inflammatory cells infiltrating the inflamed regions (Figure 6A; arrowheads). C3 and C4 were diffusely distributed within the interstitial spaces and on some inflammatory cells. By contrast, little immunoreactivity was detected in the noninflamed regions. When the aortic specimens were double stained with fluorescent antibodies against FCN1 and CD68 (a monocyte-specific marker) (Figure 6B), most FCN1-positive cells were also positive for 
Citation: Okuzaki D, Kobayashi S, Sakurai MA, Torigata K, Okamoto A, et al. (2012) Ficolin 1 Expression is Elevated in the Peripheral Blood Mononuclear Cells of Takayasu's Vasculitis Patients. J Mol Biomark Diagn 2:125. doi:10.4172/2155-9929.1000125

A

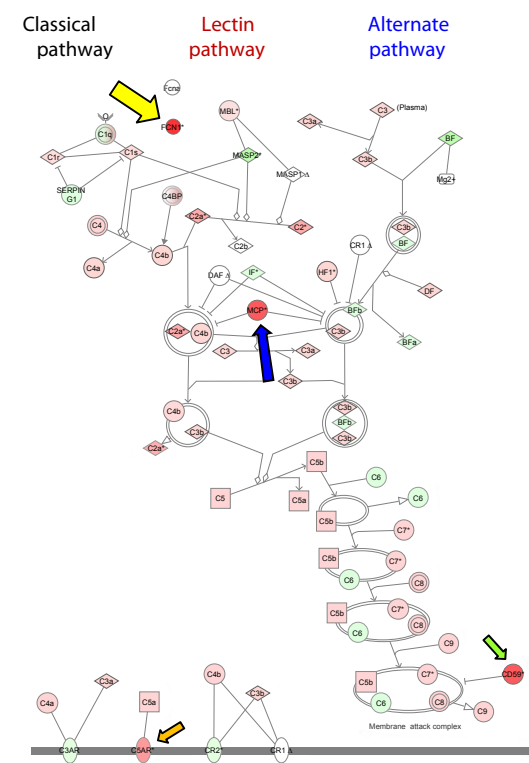

B

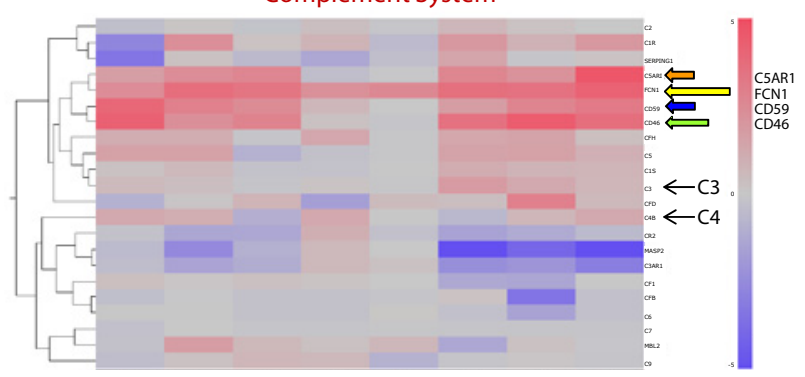

Patient: \#1 $\quad$ \#2 $\quad$ \#3 $\quad \# 4 \quad \# 5 \quad \# 6 \quad \# 7 \quad \# 8$

Figure 2: Expression profiling of the microarray data for complement system genes expressed by the eight TA patients. (A) Pathway analysis of complement system genes using Ingenuity Systems IPA software. A network pathway is a graphical representation of the molecular relationships between molecules. Molecules are represented as nodes, and the biological relationship between two nodes are represented as an edge (line). All edges are supported by at least one reference from the literature, a textbook, or by canonical information stored in the Ingenuity Knowledge Base. The intensity of the node color indicates the degree of up- (red) or down- (green) regulation. Nodes are displayed using various shapes that represent the functional class of the gene product. Edges are displayed with various labels that describe the nature of the relationship between the nodes. Pathway analysis of complement system genes identified FCN1 (yellow arrow) as the most conspicuously up-regulated gene in TA patients. Membrane cofactor protein (MCP/CD46; blue arrow), CD59 (green arrow) and C5AR (orange arrow) were moderately up-regulated in TA patients. (B) Mosaic tile representation of genes involved in the complement system. The mosaic tile for FCN1 is denoted by a yellow arrow. Tile colors indicate the mean relative transcript levels in PBMCs from TA patients and normal controls: blue corresponds to a log2 ratio of -5 (down-regulation), red corresponds to a $\log 2$ ratio of 5 (up-regulation), intermediate values are represented by shades of red (pink) or blue. Gray indicates no change (see the rightmost color bar).

CD68 (Figure 6B; arrowheads), indicating that the cells were monocytic cells, such as macrophages or dendritic cells, which are attracted to the inflamed regions. Taken together, these results suggest that FCN1 is a useful TA-related diagnostic marker.

\section{Discussion}

The present study reports the identification of candidate genetic markers for TA from RNA isolated from PBMCs, which may be useful for diagnosing and understanding the basic pathogenesis of the disease. These genes were FCN1 (Figures.1-2), STAT1, PSMB8, IRF1, IRF9 (Figure 3), IKBKG, MYD88 and TLR6 (Fig. 4). FCN1 appears to be the most important because its mRNA levels were increased more than four-fold in PBMCs isolated from all eight TA patients compared with those in healthy volunteers (Figure 1A). Moreover, increased expression of FCN1 protein was observed in the inflamed regions of surgical aorta specimens from $80 \%$ (4/5) of unrelated TA patients (Figure 6). These results suggest that FCN1 levels in PBMCs may serve as a marker for the diagnosis of TA. Since an anti-FCN1 antibody recognized FCN1 protein overexpressed by CD68-positive monocytes (Figure 6), immunoblotting of whole leukocyte proteins could also be used to diagnose TA, if a novel, simple and easy tool such as LeukoCatch [13] is employed.

The complement system is a part of the innate immune system, which recognizes and eliminates pathogens via direct killing and/or stimulation of phagocytosis. The complement system comprises more than 30 serum and cellular proteins, including ficolins, which function as recognition molecules in the lectin complement pathway. Three ficolins have been identified in humans: FCN1, FCN2, and FCN3. FCN1, a soluble collagen-like protein primarily expressed by peripheral blood leukocytes and bone marrow cells, is involved in innate immune defenses, and its genetic polymorphism appears to be associated with

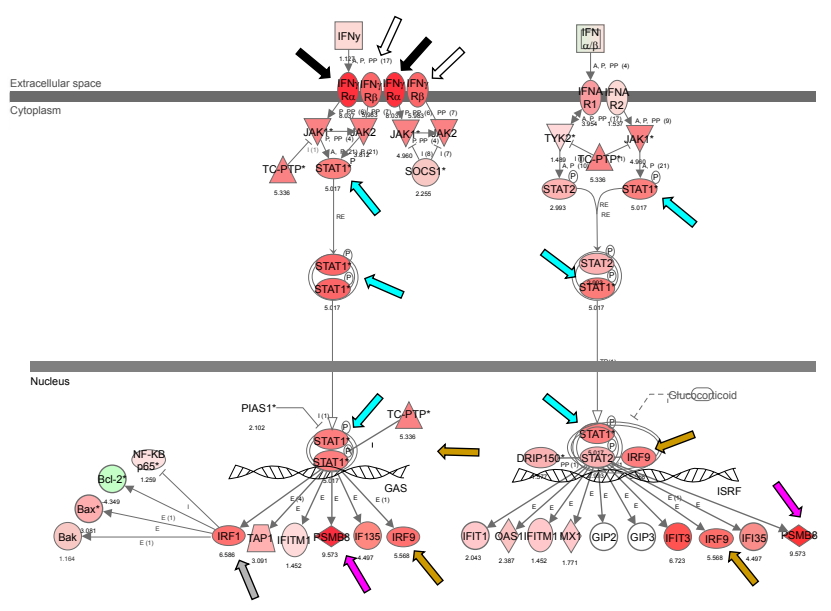

B Interferon signaling pathway

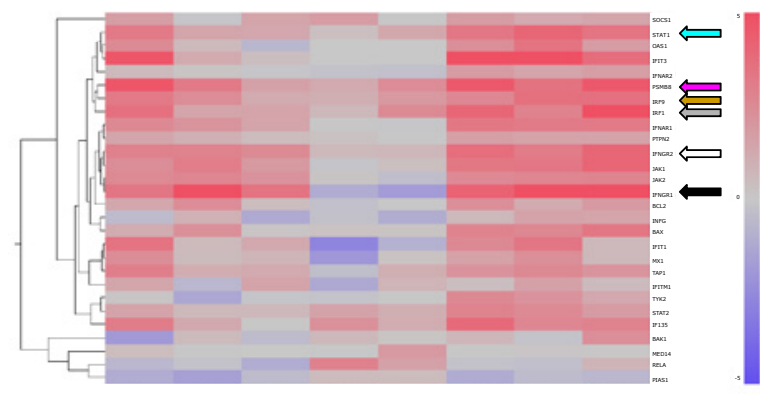

Patient: \#1 \#2 \#3 \#4 \#5 \#6 \#7 \#8

Figure 3: Expression profiling of the interferon signaling pathway. Pathway analysis $(A)$ and heat maps $(B)$ identified several genes whose mRNA levels were augmented in the majority of TA patients. These gene are STAT1 (turquoise arrow), PSMB8 (pink arrow), IRF1 (gray arrow), IRF9 (ocher arrow), ilFGR1/IFGRa (black arrow) and IFGR2/IFGR $($ white arrow). Heat mapping revealed that STAT1, PSMB8, IRF1, IRF9 and IFGR1 showed increased signals in all eight TA patients, with a moderate increase noted in patients \#3, \#4 and \#5. IFGR2 showed weak signals in patient \#4 and \#5. 
Citation: Okuzaki D, Kobayashi S, Sakurai MA, Torigata K, Okamoto A, et al. (2012) Ficolin 1 Expression is Elevated in the Peripheral Blood Mononuclear Cells of Takayasu's Vasculitis Patients. J Mol Biomark Diagn 2:125. doi:10.4172/2155-9929.1000125

Page 6 of 7

immunodeficiency [14]. Like other ficolins (FCN2 and FCN3) and mannose-binding lectins, whose mRNA levels were low in both TA patients and healthy volunteers (with no significant difference between them; data not shown), FCN1 binds sugar structures or acetylated compounds present on microorganisms and dying host cells, thereby activating the lectin complement pathway [15]. Indeed, FCN1 forms a pathogen sensor-cum-signal transducer by docking constitutively onto a monocyte transmembrane receptor, $\mathrm{G}$ protein-coupled receptor 43 (GPCR43). Upon encountering microbial invaders, the FCN1-GPCR43 complex interacts with C-reactive protein (CRP) via a conformational change in FCN1, which is induced by mild acidosis at the local site of infection, thereby activating the NF- $\mathrm{KB}$ cascade to upregulate IL- 8 production [16]. Thus, the overexpression of FCN1 observed in all TA patients may reflect microbial invasion.

Complement activation appears to be involved in the pathogenesis of other systemic autoimmune diseases [17]. Enhanced FCN1 mRNA levels were also detected by qRT-PCR in the PBMCs of patients with other autoimmune diseases, such as inflammatory bowel disease (IBD), although the enhanced mRNA levels were less marked than in TA [18]. We also detected slightly upregulated FCN1 mRNA levels in other forms of vasculitis (data not shown). Thus, upregulated FCN1 mRNA levels are not specific for TA, but rather represent a disease-nonspecific inflammatory process. However, considering the more than 4-fold increase in FCN1 mRNA levels detected in all eight TA patients (Figure. 1) and the increased FCN1 protein levels in the inflamed regions of

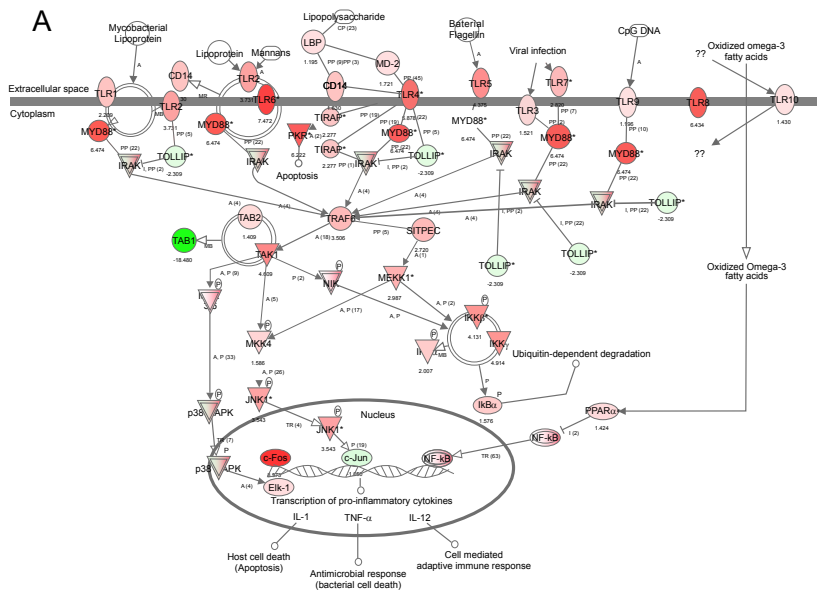

B

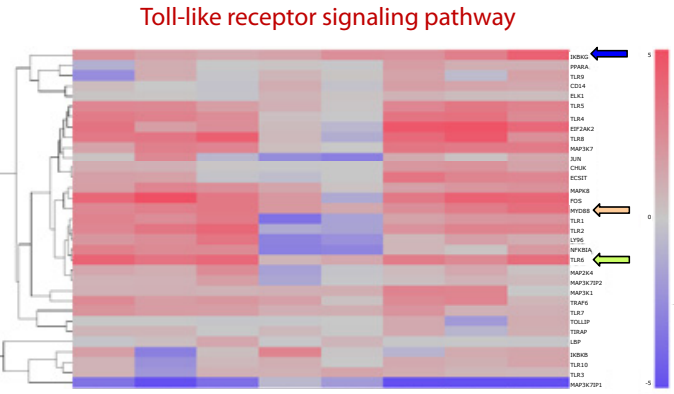

Patient: \#1 \#2 \#3 \#4 \#5 \#6 \#7 \#8

Figure 4: Expression profiling of the toll-like receptor signaling pathway. Pathway analysis (A) and heat maps (B) identified several genes whose mRNA levels were augmented in the majority of TA patients. These genes are IKBKG (navy arrow), MYD88 (pale brown arrow) and TLR6 (pale green arrow). All showed enhanced signals in all eight TA patients, although their signal intensity was relatively weak.

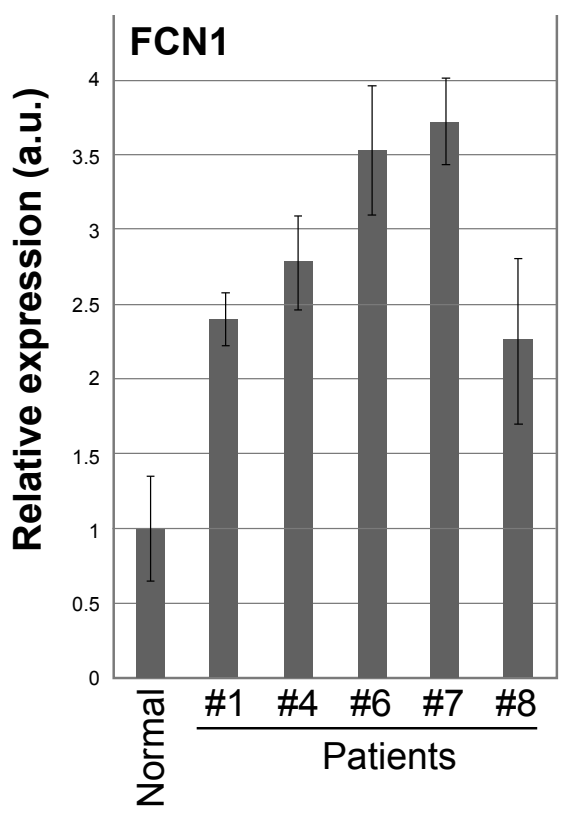

Figure 5: FCN1 mRNA levels in TA patients. The vertical axis indicates the relative intensity of the expression level (arbitrary unit: a.u.) measured by qRT PCR. The horizontal axis indicates the patients.
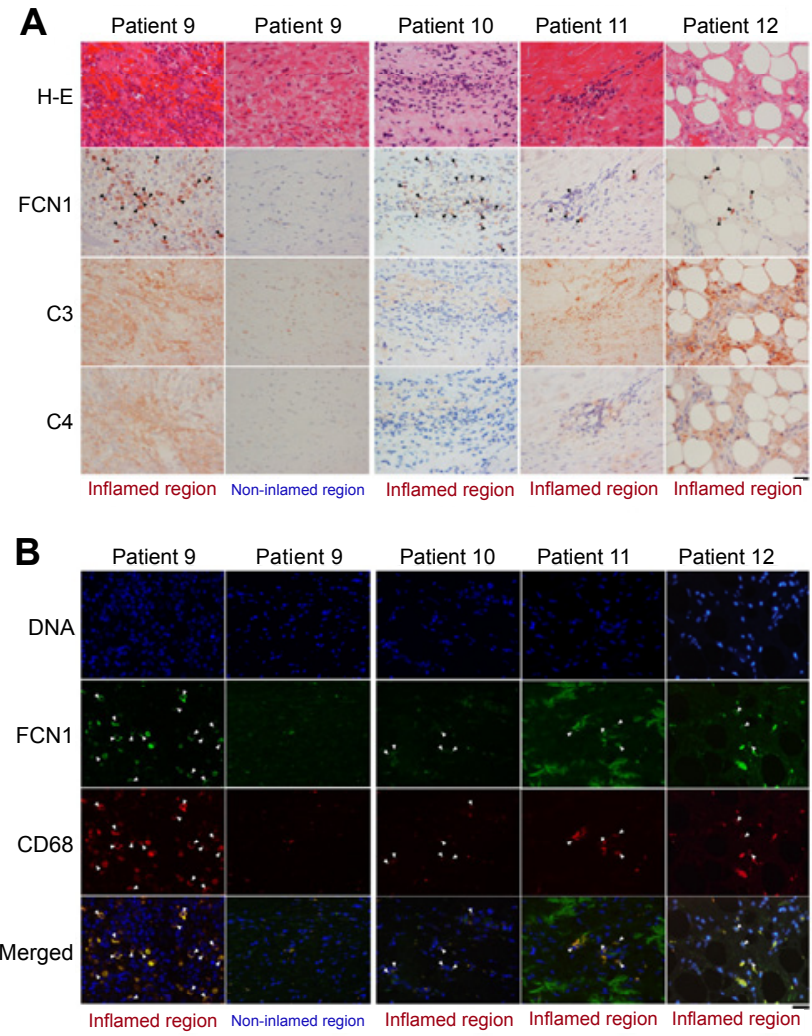

Figure 6: Immunodetection of FCN1, C3 and C4 in the aortae of patients with TA. (A) Four serial sections of aorta from Patients 9-12 were stained with H\&E or immunostained with antibodies against FCN1, C3, and C4. Arrowheads indicate representative cells reactive with anti-FCN1. (B) Sections were incubated with antibodies against FCN1 and CD68 and visualized with Cy2 and Cy3, respectively. Arrowheads indicate double-positive cells. Bar= 100 $\mu \mathrm{m}$. 
surgical aorta specimens from $80 \%$ of unrelated TA patients (Figure. 6), FCN1 may serve as a marker for the diagnosis of TA.

It is notable that the mRNA levels of at least five genes (STAT1, PSMB8, IRF1, IRF9 and IFGR1) that regulate the interferon signaling pathway, a hallmark of various autoimmune rheumatic diseases [19], were enhanced in all eight TA patients (Figure 4). Since interferon plays an important role in the first line of defense against viral infections, this suggests that TA patients may have generated a response to a previous acute viral infection. Moreover, increased mRNA levels for at least three of the genes (IKBKG, MYD88 and TLR6) that control the toll-like receptor signaling pathway or innate immunity [20] were also observed in all eight TA patients. Thus, it appears that all TA patients may have had previous viral infections, which activated their innate immunity.

We previously reported that the mRNA levels of at least four lysosome/autophagy-related genes were conspicuously enhanced in PBMCs from patients affected by Churg Strauss Syndrome (CSS), another rare form of vasculitis [21,22], and proposed that the mounting of an effective defense against invading microorganisms by lysosomes in blood cells may be involved in the pathogenesis of CSS [12]. In other autoimmune diseases, such as systemic lupus erythematosus and idiopathic thrombocytopenic purpura, mRNA levels for the antibacterial peptide, defensin 3 , and several interferon-related genes were found to be up-regulated in the PBMCs from many patients, which also suggest an effective defense against invading viruses [2325]. We previously identified several immune-responsive genes that were conspicuously enhanced in rheumatoid arthritis patients [26]. However, increased mRNA levels for complement factors, including FCN1, were not apparent in these autoimmune diseases. Taken together, we conclude that the up-regulation of FCN1 may serve as a relevant diagnostic marker for TA.

\section{Acknowledgments}

We thank the patients and healthy volunteers who participated in this study. We also thank Ms. Kana Ooi for technical assistance with cDNA microarray analysis and Dr. Patrick Hughes and Ms. Nicola Edwards of Bioedit Ltd. for critical reading of the manuscript.

\section{Funding}

This work was primarily supported by a grant-in-aid from the Health Science Research grant from the Ministry of Health and Welfare of Japan. This work was also supported in part by grants-in-aid to Hiroshi Nojima from the Bio-Medical Cluster Project In Saito, Innovation Plaza Osaka of the Japan Science, and Technology Agency (JST), Scientific Research on Priority Areas "Applied Genomics", Scientific Research (S), Exploratory Research, and the Science and Technology Incubation Program in Advanced Regions from the Ministry of Education, Culture, Sports, Science and Technology of Japan.

\section{Supplementary Materials}

Supplementary material is available online.

\section{Author Contributions}

HN made contributions to conception and design of this study and drafted the manuscript. DO performed DNA microarray analysis. SK collected patients' blood and performed relevant clinical research. MAS and Al contributed to pathological analysis. $\mathrm{AO}$ and $\mathrm{KT}$ participated in data analysis on quantification of mRNA levels including qRT-PCR. TM and HD prepared surgical aorta specimens and performed relevant clinical research. All authors read and approved the final manuscript.

\section{References}

1. Direskeneli H, Aydin SZ, Merkel PA (2011) Assessment of disease activity and progression in Takayasu's arteritis. Clin Exp Rheumatol 29(1 Suppl 64): S8691.

2. Brunner J, Feldman BM, Tyrrell PN, Kuemmerle-Deschner JB, Zimmerhack LB, et al. (2010) Takayasu arteritis in children and adolescents. Rheumatology 49: $1806-1814$
3. Mason JC (2010) Takayasu arteritis--advances in diagnosis and management Nat Rev Rheumatol 6: 406-415.

4. Kobayashi S, Fujimoto S, Takahashi K, Suzuki K (2010) Anti-neutrophil cytoplasmic antibody-associated vasculitis, large vessel vasculitis and Kawasaki disease in Japan. Kidney Blood Press Res 33: 442-455.

5. Miller DV, Maleszewski JJ (2011) The pathology of large-vessel vasculitides Clin Exp Rheumatol 29: S92-98.

6. Blockmans D (2011) PET in vasculitis. Ann N Y Acad Sci 1228: 64-70

7. Kobayashi S, Ito A, Okuzaki D, Onda H, Yabuta N, et al. (2008) Expression profiling of PBMC-based diagnostic gene markers isolated from vasculitis patients. DNA Res 15: 253-265

8. Okuzaki D, Fukushima T, Tougan T, Ishii T, Kobayashi S, et al. (2010) Genopa тм: a novel hollow fiber array for focused microarray analysis. DNA Res 17 369-379.

9. Lv N, Dang A, Zhu X, Liu Y, Liu Y, et al. (2011) The role of tumor necrosis factor- $\alpha$ promoter genetic variation in Takayasu arteritis susceptibility and medical treatment. J Rheumatol 38: 2602-2607.

10. Jennette JC, Falk RJ (2004) The coming of age of serologic testing for antineutrophil cytoplasmic autoantibodies. Mayo Clin Proc 69: 908-910.

11. Dhople V, Krukemeyer A, Ramamoorthy A (2006) The human beta-defensin-3 an antibacterial peptide with multiple biological functions. Biochim Biophys Acta 1758: 1499-1512.

12. Tougan T, Onda H, Okuzaki D, Kobayashi S, Hashimoto H, et al. (2008) Focused microarray analysis of peripheral mononuclear blood cells from Churg-Strauss syndrome patients. DNA Res 15: 103-114.

13. Okuzaki D, Kimura S, Yabuta N, Oomine T, Nojima H (2011) LeukoCatch, a quick and efficient tool for the preparation of leukocyte extracts from blood. BMC Clin Pathol 11: 9

14. Garred P, Honoré C, Ma YJ, Rørvig S, Cowland J, et al. (2009) The genetics of ficolins. J Innate Immun 2: 3-16.

15. Garred P, Honoré C, Ma YJ, Munthe-Fog L, Hummelshøj T (2009) MBL2, FCN1, FCN2 and FCN3-The genes behind the initiation of the lectin pathway of complement. Mol Immunol 46: 2737-2744.

16. Zhang J, Yang L, Ang Z, Yoong SL, Tran TT, et al. (2010) Secreted M-ficolin anchors onto monocyte transmembrane $\mathrm{G}$ protein-coupled receptor 43 and cross talks with plasma $\mathrm{C}$-reactive protein to mediate immune signaling and regulate host defense. J Immunol 185: 6899-6910.

17. Chen M, Daha MR, Kallenberg CG (2010) The complement system in systemic autoimmune disease. J Autoimmun 34: J276-J286.

18. Bovin LF, Brynskov J, Hegedüs L, Jess T, Nielsen CH, Bendtzen K (2007) Gene expression profiling in autoimmune diseases: chronic inflammation or disease specific patterns? Autoimmunity 40: 191-201.

19. Hall JC, Rosen A (2010) Type I interferons: crucial participants in disease amplification in autoimmunity. Nat Rev Rheumatol 6: 40-49.

20. Kawai T, Akira S (2011) Toll-like receptors and their crosstalk with other innate receptors in infection and immunity. Immunity 34: 637-650.

21. Borke ME, Nwagu MU, Obaseki D, Bazuaye NO (2010) Churg Strauss syndrome: a review. Niger J Med 19: 136-139.

22. Vaglio A, Moosig F, Zwerina J (2012) Churg-Strauss syndrome: update on pathophysiology and treatment. Curr Opin Rheumatol 24: 24-30.

23. Deng Y, Tsao BP (2010) Genetic susceptibility to systemic lupus erythematosus in the genomic era. Nat Rev Rheumatol 6: 683-692.

24. Provan D (2009) Characteristics of immune thrombocytopenic purpura: a guide for clinical practice. Eur J Haematol Suppl 71: 8-12.

25. Ishii $\mathrm{T}$, Onda $\mathrm{H}$, Tanigawa $\mathrm{A}$, Ohshima $\mathrm{S}$, Fujiwara $\mathrm{H}$, et al. (2005) Isolation and expression profiling of genes upregulated in the peripheral blood cells of systemic lupus erythematosus patients. DNA Res 12: 429-439.

26. Nakamura N, Shimaoka Y, Tougan T, Onda H, Okuzaki D, et al. (2006) Isolation and expression profiling of genes upregulated in bone marrow-derived mononuclear cells of rheumatoid arthritis patients. DNA Res 13: 169-183. 